\title{
FOTOGRAFÍA, LITERATURA Y ANTROPOLOGÍA EN ATACAMEÑOS DEL SIGLO XX*
}

\section{Pilar Valenzuela Rettig ${ }^{* *}$}

\section{Resumen}

En el presente estudio se analiza Atacameños del siglo XX. Registro fotográfico y etnográfico de Ivonne Valenzuela y Juan Pablo Loo, en busca de los códigos interpretativos relacionados al uso de la fotografía, que determinan el texto como un exponente de la literatura antropológica en Chile. Se analizan los elementos fotográficos, literarios y antropológicos, bajo la hipótesis de que el tratamiento de la fotografía y su relación con el texto escrito establecen códigos de lectura que obedecen al orden literario; y la macroestructura semántica al orden antropológico, constituyendo así una modalidad de mutación disciplinaria determinada, de literatura antropológica.

Palabras clave: literatura antropológica, mutación disciplinaria, fotografía, Atacameños del siglo XX.

\section{Photography, Literature AND ANTHROPOLOGY IN ATACAMEÑOS DEL SIGLO XX}

\begin{abstract}
In the present study analyzes the book Atacameños del siglo XX. Registro fotográfico $y$ etnográfico of Ivonne Valenzuela and Juan Pablo Loo, seeking interpretive codes related to the use of photography, which determine the text as an example of the anthropological literature in Chile. Elements are analyzed: photographic, literary and anthropological, under the hypothesis that photographic processing and the relationship between photography and poem have a literary code, semantic macrostructure has a code anthropological, so that the text is a form of disciplinary mutation is anthropological literature.
\end{abstract}

Keyword: anthropological literature, disciplinary mutation, photography, Atacameños del siglo XX. 


\section{Introducción}

Atacameños del siglo XX. Registro fotográfico y etnográfico (FONDARTChile, 1998), corresponde a un texto ambiguo, que desconcierta al momento de intentar definirlo dentro de un ámbito. Si bien su textualidad se basa en el verso, por tanto, en poesía, la incorporación de la imagen fotográfica y el tema bajo el cual se establece la conexión entre palabra e imagen, parece remitir al orden del pensamiento antropológico.

El objetivo de este artículo es determinar los códigos que, en relación a la fotografía, justifican una lectura de la obra como literatura antropológica. La metodología corresponde a un análisis semiótico apoyado en bibliografía. La hipótesis que conduce esta investigación es que el tratamiento de la fotografía y su relación con el texto escrito establecen códigos de lectura que obedecen al orden literario; y la macroestructura semántica ${ }^{2}$ al orden antropológico, constituyendo así una modalidad de mutación disciplinaria determinada: literatura antropológica.

La postura semiótica desde la cuál se realiza el análisis del texto se basa en los conceptos de código y signos de Umberto Eco (1995). Este estipula que código corresponde a una regla que asocia los elementos de un s-código a los elementos de otro o más s-códigos, en cuanto s-código corresponde a: una serie de señales reguladas por leyes combinatorias internas, definido como "sistema sintáctico"; una serie de nociones y contenidos de una posible comunicación, definido como "sistema semántico", y una serie de posibles respuestas de comportamiento por parte del destinatario (63-66). Los signos corresponden a "[...] los resultados provisionales de reglas de codificación que establecen correlaciones transitorias en las que cada uno de los elementos está, por decirlo así, autorizado a asociarse con otro elemento y a formar un signo sólo en determinadas circunstancias previstas por el código" (84).

Bajo estos conceptos se entiende la fotografía, el texto escrito y la obra en su totalidad, como signos cuya interpretación requiere de unos códigos, que establezcan cómo interpretarlos. Atacameños del siglo XX

2 Término utilizado por Van Dijk (1993) para referirse a la reconstrucción teórica de nociones como tema o asunto del discurso, que dan cuenta del contenido global de este (43-57). 
es una obra que presenta un carácter ambiguo en relación a los códigos necesarios para la interpretación. Los elementos están presentados de manera interdisciplinaria, con reglas provenientes de la disciplina antropológica (macroestructura semántica, búsqueda de la fotografía, trabajo de antropólogo y registro fotográfico) y provenientes de la literatura (tratamiento artístico, texto escrito relacionado a imagen, entre otros), provocando desconcierto y duda en el lector competente, quien es capaz de vislumbrar ambos conjuntos de códigos. Esta situación lleva a la incertidumbre de interpretar el uso de la fotografía, y el libro en su conjunto, como antropológico o literario. Ante este desconcierto surgen los conceptos de mutación disciplinaria, antropología poética y literatura antropológica, como posibilidad de aclaración y lugar a partir del cual establecer un nuevo código para conjugar los signos presentes en el texto que, desde una sola disciplina, se presentan fragmentados, y desde las disciplinas por separado, inconclusos y desconcertantes.

Como antecedente interdisciplinario cabe destacar que Ivonne Valenzuela posee conocimientos de ambas disciplinas. Estudió antropología en la Universidad Austral de Chile (1989 a 1994) donde participó en diversas actividades literarias, formó parte del grupo literario Domingo 7, fue codirectora de la revista Pasquina Poética e integrante de la Coordinadora de Cultura de la Federación de Estudiantes en 1997. Publicó poemas en revistas y volúmenes grupales. Luego se trasladó al norte de Chile y allí publicó dos libros de poesía antropológica, en colaboración con el fotógrafo Juan Pablo Loo: el libro en estudio y Gracias por el favor concedido. Las Animitas de Evaristo Montt, Elvira Guillén y Juana Guajardo (2008) (Carrasco, 2011: 6-7).

Las obras de los autores han sido estudiadas por Miguel Alvarado (2001) que considera Atacameños del siglo XX como parte del corpus de su tesis doctoral sobre antropología poética y, posteriormente (2009), realiza un ensayo sobre el segundo texto. También Iván Carrasco los ha estudiado, presentando una reseña (2009), una ponencia (2011) y un artículo (2012) donde se realiza una interpretación de Atacameños del siglo XX, en los cuales destaca su visualidad desde la noción de literatura y poesía antropológica ${ }^{1}$.

1 En este artículo Carrasco cita el presente estudio en su versión manuscrita (2011). 


\section{La ambigüedad desde la mutación disciplinaria:} antropología poética versus literatura antropológica

Atacameños del siglo XX se presenta como un texto ambiguo, bajo la mirada conceptual de Augé (1996: 37-38), para quien el término "ambigüedad" se utiliza para designar algo que todavía no se logra calificar, que no posee un estatus científico tan seguro, siendo provisional y, de esta manera, científicamente más prometedor, debido a la necesidad de un nuevo término y a la presencia de una promesa de superación. La ambigüedad en la obra de Valenzuela y Loo se manifiesta en el desconcierto que se produce al presentar la unión de elementos literarios, antropológicos y fotográficos. Ante esta gama de signos y códigos, el lector no puede clasificar la obra como literaria, antropológica ni fotográfica, cayendo en el desconcierto y en la necesidad, como bien expresa Augé, de un "nuevo término" que se vislumbra como "superación".

La situación de ambigüedad es abordada por Iván Carrasco (2002, 2003, 2007, 2010a y b) desde el concepto de "mutación disciplinaria", una estrategia que consiste en la modificación de las reglas, modalidades, materias y procedimientos de conformación de textos de una disciplina artística, científica o filosófica, provocada por el traslado desde otra u otras disciplinas de la misma o distinta condición. El resultado es la confusión de ámbitos disciplinarios, géneros y tipos de discurso. Desde el campo de la literatura, el autor considera que esta, cuanto disciplina artística, presenta una apertura permanente a la variedad, experimentación y transtextualidad, lo que ha favorecido que genere nuevas formas de discurso que han sido imitados o han coincidido con desarrollos de conocimiento y disciplinas de otras áreas (2010a:10).

El concepto de mutación disciplinaria, asimila y da una explicación teórica para la problemática de mutación o ambigüedad entre disciplinas desde una mirada general, interdisciplinaria. En cuanto a la relación que se desarrolla entre antropología y literatura en Chile, podemos identificar tres manifestaciones textuales que expresan características de mutación: la antropología poética, la antropología literaria y la literatura antropológica.

El concepto de "antropología poética en Chile" surge a nivel metatextual, en el libro El umbral roto. Escritos en antropología poética (1995) del antropólogo chileno Juan Carlos Olivares. Se utiliza para 
referirse a la textualidad que se manifiesta en el libro con características antropológicas y literarias, pero que es asumida a nivel paratextual como una forma de antropología que utiliza como soporte la literatura (Valenzuela, 2012). Posteriormente, Alvarado teoriza sobre esta textualidad en su tesis doctoral La antropología poética chilena como textualidad hibrida (2001) y en una serie de artículos publicados al respecto (2000 y 2002). El autor (2001) considera que es un tipo de producción textual que inicia un nuevo género discursivo, en tanto no responde pragmáticamente al canon científico ni literario con exclusividad, considerándolo básicamente como un nuevo subgénero antropológico que presenta una relación instrumental con la literatura.

Miguel Alvarado, en su investigación doctoral, incluye el texto Atacameños del siglo XX como parte de su corpus, estableciendo un primer código desde el cual poder leer la obra. Considera (2001: 283284) que el texto une armónicamente fotografía y texto antropológicopoético, elaborando una interpretación poética desde antecedentes etnográficos (historias de vida, observaciones participativas y entrevistas que están de trasfondo implícito), donde las fotografías no corresponden al adjetivo de "etnográficas" al no presentar un carácter descriptivo ni ser obtenidas por el etnógrafo, más bien considera que son el rastro de la intimidad y del gesto de confianza y benevolencia de los atacameños a la "investigadora-poeta", quien realiza una interpretación mimética de estas, desde "la reminiscencia que a una occidental puede aportar el ver textos de un pasado que no es el suyo en un contexto cultural que también es ajeno." (284).

La antropología literaria surge como una propuesta textual que presenta Alvarado (2011) a modo de distinción de la antropología poética. Se caracteriza por ser un discurso antropológico que utiliza un lenguaje literario, sin perder el carácter teórico de la disciplina antropológica, con un énfasis en la reflexión hermenéutica y un proyecto escritural basado en la búsqueda de un lenguaje propio de las ciencias humanas latinoamericanas y de carácter intercultural (Valenzuela 2013); sin embargo, conceptualmente aún no logra diferenciarse claramente de la antropología poética, como lo observa Serón (2010) en un estudio sobre ambas antropologías.

Otro código, o regla de interpretación, que nos orienta a desambiguar y dar una lectura cabal al texto, es el que se desprende del concepto 
de "literatura antropológica" propuesto por Carrasco (2010a), quien considera la obra en estudio como parte del corpus de esta literatura. En su teoría se asimila desde la mutación disciplinaria la presencia de los pensamientos antropológicos y literarios que se manifiestan en la textualidad, se determina la literatura antropológica como un tipo de mutación literaria, un género discursivo y quizás también una tendencia literaria que aún no ha sido conocida ni canonizada por la institución literaria por desarrollarse básicamente en publicaciones, congresos y diálogos propios de los espacios de un sector de las ciencias sociales (2010a: 9). Siendo, uno de los principales rasgos que la identifican (junto con ser de autoría de antropólogo u arqueólogo), un discurso que "conlleva las condiciones suficientes para ser leído simultánea o alternativamente como texto literario y/o como texto etnográfico/ etnológico" (2010a: 13-14), donde lo antropológico no corresponde sólo a un tema o macroestructura semántica, puesto que cruza todos los niveles del texto: el discurso metadiscursivo, el estilo, los temas, el léxico, el narrador, el narratario.

Para efectos de este trabajo, determinamos el concepto de literatura antropológica, como código teórico que permite acercarnos a la lectura compleja e interdisciplinaria que requiere la obra de Valenzuela y Loo; principalmente por asumir la textualidad como mutación disciplinaria, desde donde podemos integrar los diversos códigos (antropológicos, literarios y fotográficos) bajo una sola teoría. Sin embargo, es pertinente referirnos al uso de la fotografía en el campo antropológico y literario, para, a partir de este marco teórico, analizar la presencia de la fotografía en el texto, ya desde la postura de un código de lectura formulado a partir de la literatura antropológica.

\section{La inclusión de la fotografía en el texto antropológico y en el literario}

Gluzgold (citado en Monroy 2007: 19) insiste en que el acto de ver es tanto personal como cultural, es un acto ideológico tanto del que efectuó el documento, como de quien analiza. Barthes (1986: 13) expresa que la imagen fotográfica es un mensaje sin código, puesto que no es una imagen real, sino el analogon perfecto de la realidad, debido a que entre el objeto y su imagen no es absolutamente necesario disponer de un código, no así en el estilo de producción y la opinión del lector o 
receptor, donde sí contamos con un mensaje connotado que se construye a partir de uno. En el marco del presente estudio, nos interesa determinar el código de lectura que se establece al "leer" la fotografía en relación al texto escrito, para así determinar la relación entre los códigos literarios y antropológicos bajo una sola postura, o "nuevo código": el de la literatura antropológica.

JoséGamboa(2003)nos presenta, a modogeneral,losniveles de relación de las ciencias sociales con la fotografía, expresando que la fotografía puede presentarse como una técnica o instrumento para el registro de información; un mecanismo para la difusión de la información; un tema u objeto de estudio o como una rama de la antropología denominada antropología visual. Desde estas relaciones, el concepto de antropología visual se nos muestra como una posibilidad de interpretación. Esta, según Anna Casanova (1993: 86), corresponde a una subdisciplina de la antropología que nace en la década de los 60, centrada en el análisis del valor de la imagen como registro de observación directa y el uso de medios audiovisuales como método de observación y fuente de investigación de campo. La autora distingue la fotografía "antropológica" de la "histórica", en cuanto la antropológica es fruto de una intencionalidad específica al obedecer a un interés científico y es obtenida durante la investigación con un carácter de soporte ilustrativo, mientras que la histórica carece de dicha intencionalidad. Según esta clasificación, en Atacameños del siglo XX se presentan fotografías históricas, puesto que como manifiesta Alvarado en su estudio del texto (2001: 283) no podemos definirlas como etnográficas al no corresponder a imágenes obtenidas durante el trabajo de campo. Por tanto, la incorporación de la fotografía con un interés antropológico se acerca a los códigos de la antropología visual, a pesar de corresponder a una fotografía histórica; sin embargo, el texto poético no corresponde a un texto asimilable desde el código de esta subdisciplina de la antropología.

En cuanto a la fotografía en relación a la literatura, esta se asume como un signo que se puede incluir en el nivel gráfico del texto literario, acompañando o sustituyendo el lenguaje escrito. Óscar Galindo (2007) manifiesta que la expansión de los soportes lingüísticos como base de la escritura poética constituye una de las claves de la poesía de la vanguardia y es inseparable de la historia de la literatura desde Carroll y Mallarmé hasta la actualidad. En el caso de la literatura chilena, basta considerar 
la La Nueva Novela (1977) de Juan Luis Martínez como ejemplo de la incorporación de la fotografía, y otros elementos, al texto poético.

Se puede establecer entonces que es totalmente válida y coherente una lectura de la fotografía como parte del texto global, desde códigos provenientes de la teoría literaria. Si se accediera al texto sólo a nivel de formas, estableciéndolo como la unión de fotografía y texto poético, podríamos catalogar el texto como literario, puesto que su nivel antropológico aún no estaría presente. En este sentido, bajo esta lectura superficial, la presencia del verso nos hace reconocer un texto poético y, por ende, asumimos la fotografía como parte del texto literario. Se puede llegar a establecer una dependencia del texto fotográfico al poético, o simultaneidad de códigos, puesto que el texto, a primera lectura, se nos presenta como un texto literario, no como un texto de catálogo de fotografías, en donde la fotografía resaltaría sobre un texto escrito que cumpliría una función descriptiva o explicativa de la foto, cuyo caso esperaríamos una síntesis del lenguaje escrito, y no un poema.

\section{Literatura antropológica: un código de lectura para Atacameños del siglo XX}

Asumiendo el carácter ambiguo de la obra en estudio, se vislumbra en la teoría de la literatura antropológica un código que orienta su lectura en cuanto se asume como una textualidad que pone en manifiesto una mutación disciplinaria, donde los códigos o saberes antropológicos y literarios se aúnan en pos de un texto que se comunica a nivel científico (por medio de códigos antropológicos) y a nivel literario (mediante códigos que obedecen a un texto poético). Así lo entiende Carrasco (2011) al considerar que Atacameños del siglo XX, junto con Karra Maw`n (1984) de Clemente Riedemann y Metales Pesados (1998) y Alto Volta (2007) de Yanko González constituyen una manifestación modélica de la poesía antropológica, por ser verdaderos poemas cuya dimensión semántica se refieren a temas o problemas característicos del discurso etnográfico, presentando un desarrollo del aspecto gráfico del poema (a través de fotografías, dibujos u otros elementos gráficos o grafémicos) para apoyar temas etnográficos, un estilo interdisciplinario, transtextual e intermedial y la condición de textos mutantes y fronterizos entre la poesía y la antropología donde el sujeto lírico usa métodos de 
observación y escritura semejantes a los del trabajo de campo, diario de viaje o cuaderno de notas.

Iniciamos el análisis con la identificación de la macroestructura semántica del texto. En el texto poético y fotográfico esta se orienta a las vivencias y recuerdos de los atacameños del siglo XX. Desde el recuerdo de los hablantes poéticos, se presenta un desarrollo temporal, desde el pasado conformado por pastores, ovejas, algarrobos, minga, arrieros, la oscurana, pasando por el progreso que marca la llegada del tren, marcando una etapa donde ya no llegan los toros, se acaba la alfalfa, la forma de economía cambia, hasta la llegada de la modernidad, donde todo se reemplaza:

Todo se reemplaza / el burro por la carreta / la carreta por el camión / el colchón por la turbina eléctrica / el agua de río por la botella mineral / la paja brava por el brillo de las calaminas / el viaje a buscar leña por el balón de lipigás / la cal por las pinturas de la ferretería San Pedro / las acequias de tierras por los canales revestidos / la huella trompera por una columna vertebral de cemento / y aún con los llamos pasando el cerro / no vaya a ser que también se vuelva otra cosa ese paisaje ("La modernidad...", 31)

En la macroestructura semántica del recuerdo, el "olvido" se presenta como una constante que pone en riesgo la memoria. Si el pueblo vive y revive a través del recuerdo estampado en palabra e imagen fotográfica, el olvido sugiere su anulación; y ante esta posibilidad surge la voz indígena transformada en plegaria. El último poema del libro se titula "Para no olvidar", y corresponde a una imploración por mantener el recuerdo. Desde la cultura del atacameño, el poema se construye como plegaria a la Pachamama y como rezo a Dios: "Elevamos una larga plegaria a la pachamama, / con hojas de coca copal y vino / decimos juntos padre nuestro / guarda señor nuestro pueblo / protégelo del olvido / siempre es por nuestro olvido" (77).

En concordancia con la macroestructura semántica se presenta la voz del hablante indígena, remplazando la voz del autor antropólogo. La voz del indígena es una voz múltiple, polifónica: diversas voces asumen su lugar en el recuerdo del pueblo, relatando las vivencias que se relacionan temáticamente con la imagen fotográfica. Un ejemplo de esta relación 
entre palabra e imagen fotográfica se presenta claramente en el poema "Para contar los días hasta hoy"3. El texto verbal es antecedido por una fotografía de una joven que posa para la cámara junto a un carnero en un jardín, y se presenta la voz de la muchacha a través del relato en primera persona y la alusión directa a la fotografía: “Como fue que se nos pasó el tiempo / tan rápido que parece que no fuera yo / la de la foto / con falda y peinado de moda" (67). Con este poema ilustramos la relación temática que se establece entre el texto verbal, establecido como "recuerdo del pueblo atacameño", y la fotografía, espacio donde se manifiesta el elemento central del recuerdo. En este caso, lo verbal se manifiesta en la fotografía de la mujer que se presenta como hablante en el texto poético.

Podemos presentar, como otro ejemplo de la relación establecida entre fotografía y poema, el poema "Guanaco" ${ }^{4}$. En el texto escrito se presenta un hablante identificado solamente con el pronombre personal en primera persona plural (nosotros), que realiza un viaje en bus, rumbo a la ciudad, y relata la presencia de un guanaco macho en el paisaje; en la fotografía se observa un guanaco en un contexto de paisaje árido y extenso. En otro poema, titulado "En el cementerio del pueblo" ${ }^{5}$, un hablante no identificado se dirige al receptor para describir el cementerio. En la fotografía se observa un caballero de sombrero que da la espalda para observar el cementerio, que se constituye como la imagen general, identificado por las cruces.

En cuanto al tratamiento de las fotografías, éstas ocupan una página paralela al texto escrito con la cual se relaciona temáticamente; se presentan en tonalidades que van del blanco al negro; el contorno de las fotografías presenta límites difusos y parte de la imagen se utiliza como fondo para la presentación del texto escrito 6 . A través de este tratamiento se refuerza el tema del recuerdo, por adquirir el signo de lo antiguo, la ausencia de color y el límite difuso, que podemos relacionar a las fotografías que a través de los años se gastan y sufren daños en sus contornos.

\footnotetext{
3 Ver ilustración "Para contar los días hasta hoy".

Ver ilustración "Guanaco".

Ver ilustración "En el cementerio del pueblo".

Ver ilustración "Nostalgias".
} 
Otro elemento de gran significación en cuanto al carácter etnográfico de los textos son los epígrafes que anteceden a dos secciones del libro. Éstos corresponden a citas de personas que son identificadas por el nombre y se deduce que son extractos de entrevistas realizadas por un antropólogo a personas del pueblo atacameño que son identificadas por su nombre y apellido, reforzando el carácter de veracidad en cuanto el texto se crea a partir de un trabajo etnográfico que implica una investigación con metodología de observación participante y entrevistas (Cf. Carrasco 2010a). El primero dice: “'Después, yo estoy muy de acuerdo / que seamos conocidos, por todos. / Bienvenidos sean, siempre y cuando nos respeten...' María Medalla Aguilar" (4) y el segundo: " 'Es que la juventud se está yendo, desde que parte de la escuela misma, / entonces ya agarra otro ambiente, ya como que no le tira el terreno, / ya como que no se acostumbran...' Mario Ramos Selti" (43).

En una de las secciones finales del texto se presenta un paratexto que, a pesar de no poseer título, se deduce como una sección de agradecimiento. En este se expresa:

Este libro fue hecho por muchas manos y voces. Personas quienes, ya sea a través de entrevistas, de conversaciones informales, o de facilitar una fotografía familiar, entregaron su versión de San Pedro de Atacama, sus historias y sus día a día. Gracias a ellos este libro cobra vida, en un ejercicio de recuento y abstracción en donde cada foto y cada texto lleva en sí muchas otras fotos, textos y personas. (79)

En este paratexto se incluye a las personas presentadas en los epígrafes, reforzando la significación de extracto de conversación como parte de la construcción del texto: la autora "utiliza" la voz del atacameño para construir un texto poético. En los epígrafes aparece la cita, donde se presenta un autor individual, identificado con un nombre; en los poemas se presenta la voz indígena, al atacameño sin nombre, representante de la pluralidad que representa "el pueblo". Arbitrariamente, el epígrafe no se acompaña de una fotografía, no hay imagen para ilustrar al hablante identificado o su mensaje; en cambio, en los poemas sí se presenta la imagen, la fotografía como registro del mensaje que se construye en relación al poema. Podemos establecer que mediante estos procesos: la identificación del hablante con nombre y apellido, y la ilustración por 
medio de la presencia de la fotografía, se otorga significación de veracidad al texto escrito, en una especie de "referencia" del trabajo etnográfico que le antecede.

A nivel paratextual, también se presenta un signo que es posible leer desde la antropología y la literatura: el glosario. Bajo un código literario éste se presenta como signo de literatura etnocultural (Carrasco 2005a y b), donde se asume al lector como miembro de otra cultura, ajena a la presentada en el texto. El glosario se puede leer también como parte de un trabajo etnográfico, sobre todo relacionándolo con las secciones que le continúan: fuentes fotográficas y bibliográficas.

\section{Conclusiones}

En Atacameños del siglo XX. Registro fotográfico y etnográfico, la fotografía corresponde a un signo que se lee en relación al texto verbal, el que corresponde a un texto poético que se construye mediante la utilización de la polifonía como estrategia textual para representar la "voz del pueblo atacameño", en desmedro de la voz de la poeta, autora antropóloga.

En cuanto macroestructura semántica, la fotografía presenta un carácter antropológico. Esta, en relación al poema, se presenta como referente de un recuerdo y de las experiencias del pueblo atacameño; mediante los paratextos, la fotografía presenta un tema de carácter antropológico debido a que en ellos se afirma que las fotografías son recolectadas por los autores como parte de un trabajo etnográfico que antecede a la construcción del texto poético.

El uso de la fotografía es aceptado dentro de los cánones de la literatura, acompañando o reemplazando al texto escrito; sin embargo, la incorporación de la fotografía en un texto antropológico obedece a otras reglas, como las presentes en la antropología visual o en la fotografía como ilustración de un trabajo etnográfico, lo que no ocurre en la obra en estudio.

La fotografía se puede leer desde un código antropológico, relacionándola con los paratextos, en cuanto el título de la obra nos remite a un registro etnográfico que forma parte de un trabajo antropológico. El prólogo posee una autoría en relación a este campo disciplinario y contextualiza la fotografía y el texto en general, a dicho campo. Los 
agradecimientos, las fuentes fotográficas, biográficas y presentación de los autores, consideran la fotografía en relación a un trabajo etnográfico. Sin embargo, si leemos el texto en independencia de sus paratextos, se presenta como un texto literario, donde poesía y fotografía se unen bajo una misma superestructura, una macroestructura semántica y una tradición de incorporación de lo visual, imagen y fotografía, en un texto literario. Es a nivel paratextual donde se le otorga a la fotografía una relación con el trabajo etnográfico previo a la construcción textual. Por lo tanto, asumimos la fotografía como parte del texto literario a partir del código de la literatura antropológica en Chile que manifiesta que dentro de los textos se presentan dibujos, mapas y fotografías como elementos constitutivos con un carácter referencial obedeciendo a la interdisciplinariedad propia de esta textualidad.

Cumpliéndose la hipótesis, en cuanto a que el tratamiento de la fotografía y su relación con el texto poético establecen códigos de lectura que obedecen al literario; y la macroestructura semántica al antropológico, nos encontramos en posición de detallar más la hipótesis, concluyendo que son los paratextos los que se presentan como signos de un código de trabajo antropológico (etnográfico) deducible a partir de la información que estos entregan del trabajo previo a la construcción del texto.

Atacameños del siglo XX. Registro fotográfico y etnográfico se puede leer desde códigos literarios y antropológicos, sin embargo, consideramos que una lectura desde uno de los códigos no logra desambiguar la complejidad del texto, como ocurre al leerlo desde los códigos de la antropología visual, poética y/o literaria. Ante esta situación, concluimos que la teoría de la literatura antropológica en Chile, se nos presenta como un "código integrador" de los códigos literarios y antropológicos, por ser una teoría que se basa en la mutación disciplinaria e interdisciplinariedad. Afirmamos, desde este código, que el texto en estudio es una modalidad de la literatura antropológica en Chile. 


\section{Bibliografía}

Alvarado, Miguel. "Los últimos poetas de la aldea. El surgimiento de la antropología poética como posibilidad hermenéutica". Revista Austral de Ciencias Sociales 4 (2000): $78-89$.

. La antropología poética como textualidad hibrida. Tesis doctoral Universidad Austral de Chile, 2001.

. "Introducción a la antropología poética chilena". Estudios Filológicos 42 (2002): 169-183.

. "La carta encontrada. Lecturas de un libro de Ivonne Valenzuela".

Latinizarte. Revista de arte y pensamiento latinoamericano (2009): s.p. Web. 5 Agosto 2013.

. La antropología literaria. Aportes para la generación de un lenguaje intercultural. Santiago de Chile: Cuarto Propio, 2011.

Augé, Marc. El sentido de los otros. Buenos Aires: Paidós, 1996.

Barthes, Roland. Lo obvio y lo obtuso. Imágenes, gestos, voces. Barcelona: Paidós, 1986.

Casanova, Anna. "Fotografía y discurso antropológico: Inuit en Madrid, 1900". Anales del Museo de América 1 (1993): 85-98.

Carrasco, Iván. "Interdisciplinariedad, interculturalidad y canon en la poesía chilena e hispanoamericana actual". Estudios Filológicos 37 (2002): 199-210.

. "La antropología poética como mutación disciplinaria". Estudios Filológicos 38 (2003): 7-17.

. "Literatura intercultural chilena: proyectos actuales". Revista Chilena de Literatura 66 (2005a): 63-84.

. "Literatura chilena: canonización e identidades". Estudios Filológicos 40 (2005b): 29-48.

. "La mutación disciplinaria: un fenómeno de comunicación interdisciplinaria". Diálogos culturales. Interdisciplinas para la comunicación. Browne, 
Rodrigo et al. (Eds.). Sao Paulo: Annablume Editora, 2007.

. "Gracias por el favor concedido. Las animitas de Evaristo Montt,

Elvira Guillén y Juana Guajardo". Revista Austral de

Ciencias Sociales 17 (2009): 127-130.

. "Literatura antropológica chilena: fundamentos". Estudios Filológicos 46 (2010a): 9-23.

. "La literatura antropológica chilena". XVIII Congreso Internacional de Estudios Literarios. SOCHEL. Ponencia no publicada. Valparaíso, 2010b.

. "La poesía antropológica en Chile: Ivonne Valenzuela". VII Congreso Internacional de Literatura, Memoria e Imaginación Latinoamericana y el Caribe. Quito (2011). Ponencia no publicada. Quito, 2011.

. "Poesía antropológica de Ivonne Valenzuela". Anales de Literatura Chilena 17 (2012): 219-236.

Eco, Umberto. Tratado de Semiótica General. Barcelona: Editorial Lumen, 1995.

Galindo, Oscar. "Palabras e imágenes, objetos y acciones en la postvanguardia chilena". Estudios Filológicos 42 (2007): 109-121.

Gamboa, José. "La fotografía y la antropología: una historia de convergencias". Revista Latina de Comunicación Social (2003): s.p. Web. 5 Ago. 2013.

González, Yanko. Metales pesados. Valdivia: Ediciones Kultrún, 1998. . Alto Volta. Valdivia: Ediciones Kultrún, 2007.

Martinez, Juan Luís. La nueva novela. Santiago de Chile: Ediciones Archivo, 1977.

Monroy, Rebeca. "Apreciación histórica y estética de la fotografía: un reto entre lo analógico y lo digital". Historia 2 Vol. 26 (2007): 4-18.

Olivares, Juan C. El umbral roto. Escritos en antropología poética. Santiago de Chile: Fondo Matta, Museo Chileno de Arte 


\section{Precolombino, 1995.}

Riedemann, Clemente. Karra Maw’n. Valdivia: Alborada, 1984.

Serón, Marcelo. "Cuestiones y controversias en Antropología poética y Antropología literaria chilenas". Sociedad Hoy 18 (2010): 27-39.

Valenzuela, Ivonne y Juan Pablo Loo. Atacameños del siglo XX. Registro fotográfico y etnográfico. Antofagasta: FONDART, 1998.

. Gracias por el favor concedido. Las Animitas de Evaristo Montt, Elvira Guillén y Juana Guajardo. Antofagasta: Imprenta Ercilla, 2008.

Valenzuela, Pilar. "Entre antropología y literatura: paratextos de $E l$ umbral roto. Escritos en antropología poética". Acta Literaria 45 (2012): 137-151.

. El diario de viaje / campo como literatura antropológica en Chile. Tesis doctoral Universidad Austral de Chile, 2013.

Van Dijk, Teun. Estructuras y funciones del discurso. México, D.F.: Siglo XXI, 1993. 


\section{Ilustraciones}

Ilustración "Para contar los días hasta hoy":

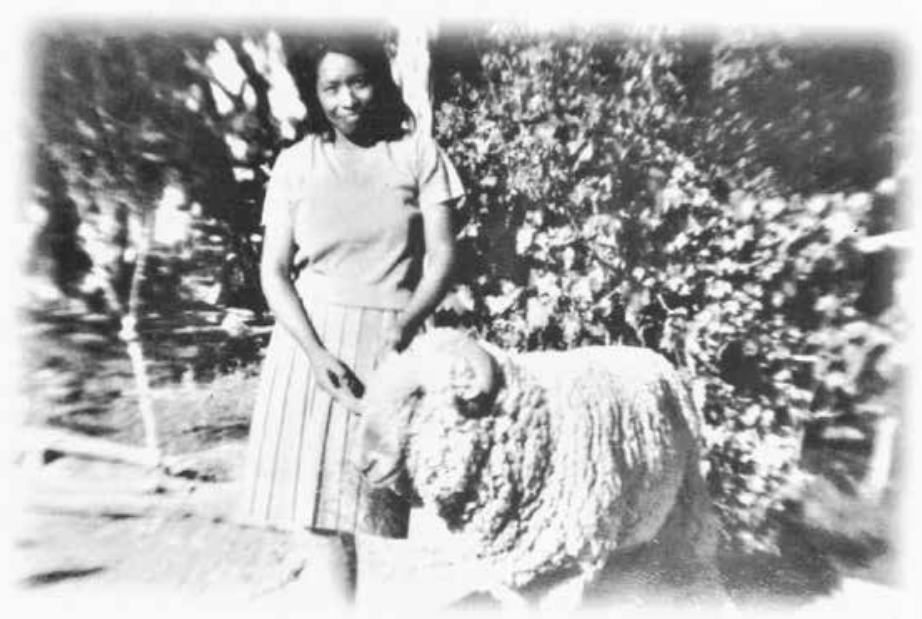

Ilustración "Guanaco":

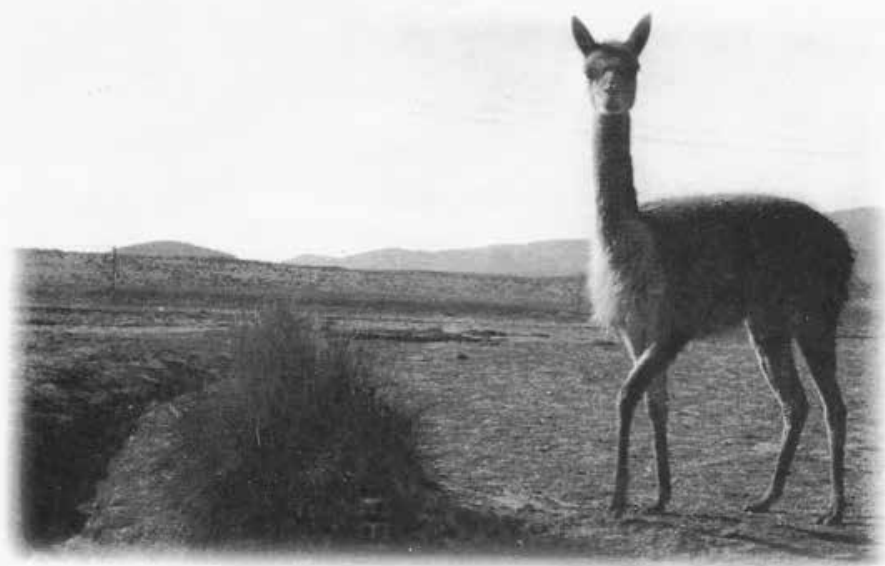


Ilustración "En el cementerio del pueblo":

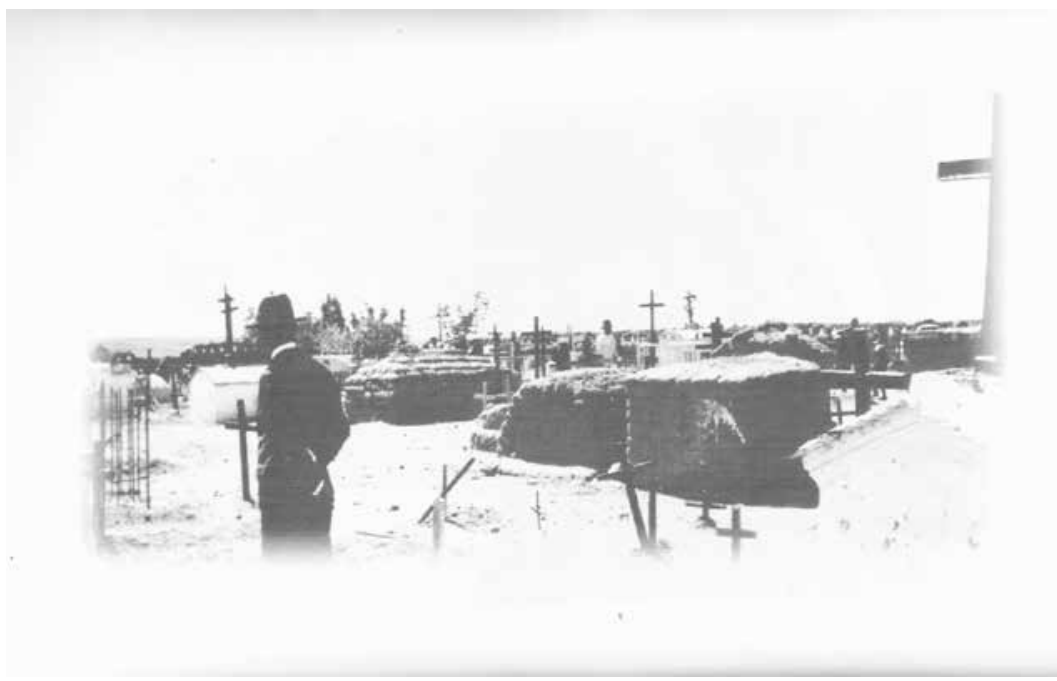

Ilustración "Nostalgias":

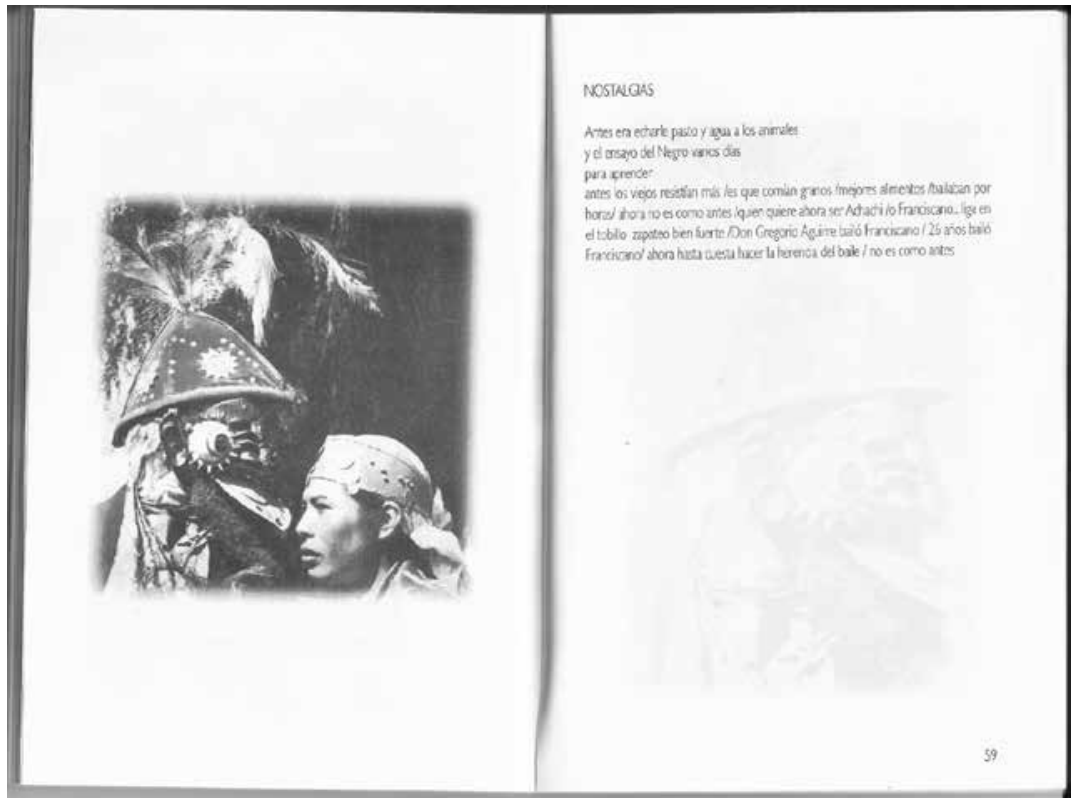

